\title{
Frozen elephant trunk surgery in acute aortic dissection
}

\author{
Roberto Di Bartolomeo, MD, Antonio Pantaleo, MD, Paolo Berretta, MD, Giacomo Murana, MD, \\ Sebastiano Castrovinci, MD, Mariano Cefarelli, MD, Gianluca Folesani, MD, and \\ Marco Di Eusanio, MD, PhD
}

\begin{abstract}
Objectives: Acute aortic dissection is a catastrophic condition, for which emergency surgery is the mainstay of therapy. In approximately $70 \%$ of patients who survive surgery, a dissected distal aorta remains, posing a risk of late aneurysmal degeneration, rupture, and malperfusion, and secondary extensive interventions are often required.
\end{abstract}

Methods: In order to improve the long-term prognosis, a more extensive intervention, the frozen elephant trunk (FET) procedure, has been introduced. This involves the simultaneous replacement of the aortic arch and antegrade stenting of the descending thoracic aorta (DTA). Although FET is assumed to produce total thoracic aortic remodeling by inducing both coverage of secondary entry tears located in the proximal DTA and obliteration of the false lumen at the proximal DTA, its role in patients with acute dissection remains controversial mostly because of its technical complexity and increased risk of paraplegia.

Results: Data available in literature show that, after FET interventions, hospital death, stroke, and spinal cord injury occur in $10.0 \%, 4.8 \%$, and $4.3 \%$ of patients with acute dissection, respectively. Available long-term data are sparse but suggest that aortic remodeling with partial or complete thrombosis of the persistent false lumen can be expected in approximately $90 \%$ of cases.

Conclusions: The FET technique is a promising approach in patients with acute dissection. Solid long-term data are warranted to validate the assumed short- and long-term benefits, but we believe that thoughtful patient selection criteria remain crucial. (J Thorac Cardiovasc Surg 2015;149:S105-9)

Acute aortic dissection is a disease that has a catastrophic impact on a patient's life. Although advances in care have translated into improved outcomes for patients with acute dissection, hospital mortality after surgery still ranges from $15 \%$ to $30 \% .^{1-3}$ For this reason, a conservative tear-oriented approach aimed at performing the simplest and shortest operation with the least adverse impact on the patient, has generally been adopted; ascending aorta (or hemiarch) replacement with resuspension of the aortic leaflets is the most common procedure. ${ }^{4}$ Nevertheless, limited aortic resections have been shown to be associated with an unsatisfactory long-term prognosis as demonstrated by a $70 \%$ occurrence of late distal aortic complications, including aneurysmal degeneration, rupture, malperfusion, and the need for extensive secondary or tertiary interventions. ${ }^{5,6}$ This has stimulated some experienced centers to

\footnotetext{
From the Department of Cardiac Surgery, S. Orsola-Malpighi Hospital, University of Bologna, Bologna, Italy.

Disclosures: Authors have nothing to disclose with regard to commercial support.

Read at The American Association for Thoracic Surgery Aortic Symposium,

New York, New York, April 24-25, 2014.

Received for publication April 18, 2014; revisions received June 26, 2014; accepted

for publication July 24, 2014; available ahead of print Sept 8, 2014.

Address for reprints: Marco Di Eusanio, MD, PhD, Cardiac Surgery Department,

Sant'Orsola-Malpighi Hospital, Universiy of Bologna, Via Massarenti 9, 40128,

Bologna, Italy (E-mail: marco.dieusanio2@unibo.it).

$0022-5223 / \$ 36.00$

Copyright (c) 2015 by The American Association for Thoracic Surgery

http://dx.doi.org/10.1016/j.jtcvs.2014.07.098
}

perform more aggressive primary operations. Recently, total arch replacement and concomitant antegrade stenting of the descending thoracic aorta (DTA) during circulatory arrest with a frozen elephant trunk (FET) has gained interest in this setting. ${ }^{7-11}$ The rationale lies in the potential for total thoracic aortic remodeling, which may result from stenting the DTA during the acute phase of aortic dissection. However, the widespread use of this approach has been tempered by the increased surgical trauma for the patient and the increased technical complexity for the operating surgeon.

\section{SURGICAL TECHNIQUE AND ORGAN PROTECTION}

Total arch replacement with the FET technique in patients with acute dissection is a highly demanding and time-consuming operation that mandates solid experience with endovascular and surgical therapies for acute dissection, and optimal methods of organ protection.

An accurate assessment of the aortic anatomy from the preoperative angio-computed tomography scan represents the first requisite of a successful procedure; the extent of the dissecting process, the exact location of the entry and reentry tears, the distribution of visceral vessels between the true and the false lumen, and the aortic diameters have to be carefully assessed. Notably, an oversized stent must be avoided in order to prevent formation of new intimal tears distal to the stent graft, which can promote 


\section{Abbreviations and Acronyms}

ASCP $=$ antegrade selective cerebral perfusion

DTA $=$ descending thoracic aorta

FET = frozen elephant trunk

TEE $=$ transesophageal echocardiography

sustained retrograde perfusion of the peri-stent false lumen, thereby inhibiting aortic remodeling of the DTA. ${ }^{12}$

Organ protection involves sophisticated methods capable of increasing tolerance to ischemia of the brain, spinal cord, myocardium, and visceral organs. We have used antegrade selective cerebral perfusion (ASCP) and moderate hypothermia according to Kazui's technique for brain protection since 1996. We lower the patient's nasopharyngeal temperature to $26^{\circ} \mathrm{C}$; we establish circulatory arrest and, through the cannulated right axillary (or innominate) and left common carotid arteries, bilateral brain perfusion is initiated at a flow rate of 10 to $15 \mathrm{ml} / \mathrm{kg} / \mathrm{min}$ and is adjusted to maintain the right radial pressure between 40 and $70 \mathrm{~mm}$ $\mathrm{Hg}$. Increasingly, we are adopting total antegrade brain perfusion with cannulation of the left subclavian artery in order to improve protection of the cervical spinal cord, which depends on the vertebral arteries. We demonstrated that up to 90 minutes of ASCP was not associated with an increased risk of adverse neurologic outcomes, leading us to believe that ASCP is the best method for protecting the brain, especially when time-consuming aortic arch reconstructions (such as FET) are undertaken. ${ }^{13}$ The main general principles for spinal cord and visceral protection include the use of hypothermia, perfusion of the left subclavian artery, cerebrospinal fluid drainage (not used in patients undergoing emergency acute dissection), prompt antegrade reperfusion of the thoraco-abdominal aorta via the arch graft as soon as the distal anastomosis is completed, and a stable and adequate perioperative hemodynamic status indicated by a mean arterial pressure greater than $70 \mathrm{~mm} \mathrm{Hg}$. In our institution, Custodiol (HTK-Custodiol; Koehler Chemi, Alsbach-Haenlien, Germany) is used for myocardial protection, which, with a single dose of 20 to $25 \mathrm{~mL} / \mathrm{kg}$, guarantees a safe myocardial ischemic time of 3 hours.

Two commercially available prostheses can be used for FET interventions: the E-vita Open Plus prosthesis (JOTEC $\mathrm{GmbH}$, Hechingen, Germany) and the Thoraflex hybrid prosthesis (Vascutek, Inchinnan, Scotland). Both consist of a proximal vascular graft (quadrifurcated in the Thoraflex and tubular in the E-vita Open Plus) and a distal stent graft. Available in different sizes and with different delivery systems, both prostheses have obtained the CE (Conformité Européene) mark, and are used extensively in acute dissection and other diseases involving the thoracic aorta. The main surgical steps include (Figure 1) total resection of the aortic arch; preparation of the distal aortic stump with obliteration of the false lumen using 4 or $5 \mathrm{U}$ stitches with pledgets inside and a Teflon felt outside; advancement of the hybrid system in the DTA over a guidewire that has been retrogradely positioned via the femoral artery into the true lumen under transesophageal echocardiography (TEE) guidance; stent graft deployment; fixation and suturing of the graft to the distal stump and arch replacement with the proximal vascular segment of the hybrid prosthesis. ${ }^{12}$ The arch vessels are reimplanted as an island with the E-vita Open Plus prosthesis and separately reimplanted to branch grafts with the Thoraflex system. The latter is indicated when the origins of the arch vessels are widely separated or are severely involved by the dissecting process.

\section{RATIONALE OF THE FET TECHNIQUE IN ACUTE DISSECTION}

In patients with acute dissection, short- and long-term benefits of FET can be identified.

In our opinion, the FET technique is a valuable adjunct to total arch replacement in patients with distal aortic malperfusion with compression of the true lumen, complex primary and reentry tears involving the distal arch or proximal descending thoracic aorta (DTA), distal arch or descending thoracic aorta rupture, an aneurysmal arch and proximal descending thoracic aorta, and a severely damaged aortic arch hampering safe distal aortic arch anastomosis. In patients with malperfusion, the rationale for the FET technique lies in its potential to fully open the compressed true lumen and to cover additional entry tears located in the proximal DTA, which maintain pressurization of the false lumen. With the other conditions, the FET hybrid prostheses facilitate surgery by avoiding the need to perform a complex and hazardous distal anastomosis, deeply performed at the level of the proximal DTA, where there is a high risk of rupture or bleeding caused by the fragile dissected aortic wall. Taking advantage of the distal stent graft segment of the FET prosthesis, a distal anastomosis can be more easily carried out at a more proximal level (proximal to the left subclavian or left carotid arteries), while still excluding the distal arch tear. ${ }^{14,15}$

There is evidence that the distal false lumen of the aorta may degenerate and become aneurysmal, rupture, or require additional extensive interventions in $60 \%$ to $90 \%$ of cases. ${ }^{5,6,16-18}$ Such disease progression seems to be related to aortic factors (the number, size, and site of reentry tears; aortic size at onset of dissection; false lumen diameter) and patient factors (young age; connective diseases; arterial hypertension), regardless of successful entry tear resection at primary surgery. ${ }^{1,19-21}$ In acute dissection, by inducing both coverage of secondary entry tears located in the proximal DTA and obliteration of the false lumen at the proximal DTA, extensive FET 


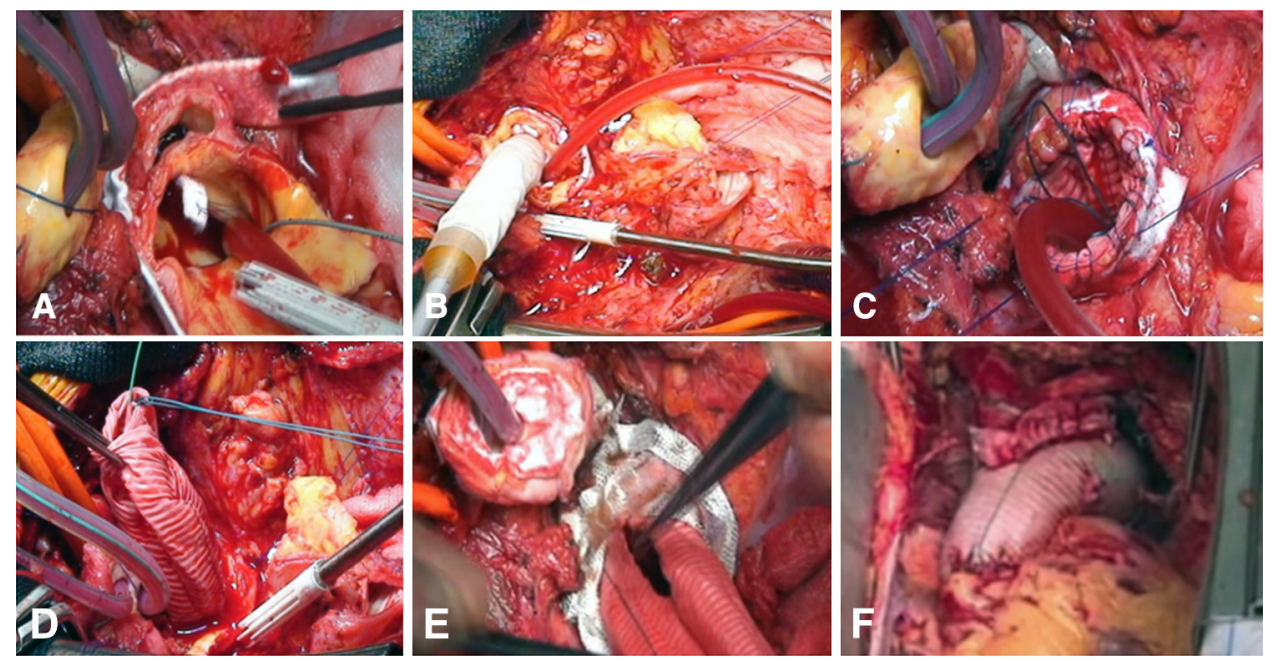

FIGURE 1. Frozen elephant trunk technique in acute aortic dissection: the main operative steps. A, The aortic arch has been resected and, under circulatory arrest and antegrade selective cerebral perfusion and moderate hypothermia $\left(26^{\circ} \mathrm{C}\right)$, the false lumen is obliterated using 4 polypropylene $(3 / 0) \mathrm{U}$ stitches with Teflon pledgets inside and 1 Teflon felt outside; B, the E-Vita Open Plus system is advanced into the descending thoracic aorta over a guide wire that was previously introduced into the true lumen of the dissection under transesophageal echocardiographic guidance; $\mathrm{C}$, after stent graft deployment, the vascular segment of the hybrid prosthesis is sutured to the distal stump using 4 running $3 / 0$ polypropylene sutures; $\mathrm{D}$, the vascular segment of the hybrid prosthesis is pulled out; $\mathrm{E}$, the island containing the origin of the arch vessels is anastomosed to the vascular graft; $\mathrm{F}$, final aortic repair.

interventions are assumed to diminish DTA dilatation, and therefore to improve long-term survival by reducing aortic-related deaths and the need for complex distal aortic reinterventions. However, although data from imaging studies already show encouraging rates of distal aortic remodeling processes, long-term clinical data are still needed to demonstrate a clear survival benefit from aggressive versus conservative management of the aortic arch and DTA at primary surgery. ${ }^{15}$ This is mostly because of the limited size of the study populations, inconsistencies in measurement techniques, and limited follow-up data beyond 5 years.

\section{EARLY AND LONG-TERM RESULTS}

We recently reviewed the results of FET surgery for DeBakey type I acute aortic dissection, focusing on in-hospital

TABLE 1. Early and follow-up outcomes after extensive DB1-AAD repair with antegrade stenting of DTA

\begin{tabular}{|c|c|c|c|c|c|c|c|c|c|c|}
\hline \multirow[b]{2}{*}{ Author } & \multirow[b]{2}{*}{ Reference } & \multirow[b]{2}{*}{$\begin{array}{c}\text { Patients } \\
\text { (n) }\end{array}$} & \multicolumn{4}{|c|}{ 30-days or in hospital } & \multicolumn{4}{|c|}{ Outcomes at follow-up } \\
\hline & & & $\begin{array}{l}\text { Death, } \\
\text { n (\%) }\end{array}$ & $\begin{array}{l}\text { PND, } \\
\text { n (\%) }\end{array}$ & $\begin{array}{c}\text { SCI, } \\
\text { n ( } \%)\end{array}$ & $\begin{array}{c}\text { Renal } \\
\text { failure, } \\
\text { n }(\%)\end{array}$ & $\begin{array}{c}\text { Mean } \\
\text { follow-up } \\
\text { (months) }\end{array}$ & $\begin{array}{c}\text { Peri-stent } \\
\text { (complete or } \\
\text { partial) false } \\
\text { lumen } \\
\text { thrombosis, } \\
\text { n }(\%)\end{array}$ & $\begin{array}{c}\text { Distal aortic } \\
\text { reoperation, } \\
\text { n }(\%)\end{array}$ & $\begin{array}{c}\text { Mortality, } \\
\text { n ( } \%) \\
\end{array}$ \\
\hline Jakob & ATS 2008;86:95-101 & 22 & $2(9.0)$ & $2(9.0)$ & 0 & $12(54.5)$ & 23 & $18(90.0)$ & $2(10.0)$ & $4(20.0)$ \\
\hline Shimamura & JTCVS 2008;135:1261-9 & 29 & $2(6.8)$ & (N/A) & $4(13.8)$ & N/A & 60 & $27(100)$ & N/A & N/A \\
\hline Pochettino & ATS 2009;88:482-9 & 36 & $5(14.0)$ & $1(3.0)$ & $3(9.0)$ & $6(17.0)$ & 16 & $24(77.0)$ & 0 & 0 \\
\hline Chen & ICVTS 2010;11:594-8 & 27 & $4(14.8)$ & $3(11.1)$ & 0 & $2(7.4)$ & 30 & $23(100)$ & $1(4.3)$ & $2(8.7)$ \\
\hline Jakob & JCS 2011;52:717-23 & 88 & $16(18.0)$ & $5(6.0)$ & $5(6.0)$ & $32(36.4)$ & - & $72(100)$ & N/A & N/A \\
\hline Sun & ATS 2011;91:1147-52 & 148 & $7(4.7)$ & $4(2.7)$ & $3(2.0)$ & $1(0.7)$ & 42 & $133(94)$ & $1(0.7)$ & $4(2.8)$ \\
\hline Uchida & EJCTS 2011;40:1066-71 & 80 & $4(5.0)$ & $2(2.5)$ & 0 & $3(3.8)$ & 74.3 & $76(100)$ & $6(7.9)$ & $5(6.6)$ \\
\hline Shi & JTCVS 2011;142:1458-63 & 46 & $1(2.2)$ & 0 & 0 & - & 14 & $45(100)$ & 0 & 0 \\
\hline Shen & EJCTS 2012;41:e12-7 & 22 & $2(9.1)$ & - & $1(4.5)$ & - & 12 & $20(100)$ & 0 & 0 \\
\hline Hoffman & JTCVS 2013;145:964-9 & 32 & $1(3.1)$ & 0 & 0 & 0 & 17 & $31(100)$ & 0 & $1(3.1)$ \\
\hline Xiao & JTCVS 2013;147:639-43 & 33 & $6(18.2)$ & 0 & 0 & $1(3.0)$ & 27 & - & N/A & $1(3.7)$ \\
\hline Shrestha & EJCTS 2013;43:406-10 & 18 & $5(27.7)$ & (N/A) & 0 & - & - & - & $2(15.4)$ & N/A \\
\hline Roselli & JTCVS 2013;145:S197-201 & 17 & 0 & $2(12.0)$ & 0 & $3(19)$ & 5 & $15(88)$ & $1(6.0)$ & 0 \\
\hline
\end{tabular}

ATS, Annals of Thoracic Surgery; JTCVS, Journal of Thoracic and Cardiovascular Surgery; ICVTS, Interactive Cardiovascular and Thoracic Surgery; JCS, Journal of Cardiac Surgery; EJCTS, European Journal of Cardio-Thoracic Surgery; PND, permanent neurologic dysfunction; SCI, spinal cord injury; N/A, not applicable. 
mortality and morbidity as well as on long-term survival, the occurrence of distal aortic remodeling, and freedom from aortic reinterventions. Based on our literature search criteria, 13 observational studies involving 598 patients were reviewed (Table 1). ${ }^{15}$

Overall, the average weighted in-hospital (or 30-day) mortality was $10.0 \%$, ranging from $0 \%$ to $27.7 \%$. Postoperative stroke occurred in $4.8 \%$ of patients (range, $0 \%-12.0 \%$ ) and spinal cord injury occurred in $4.3 \%$ of patients (range, $0 \%-13.8 \%$ ). Renal failure occurred in $10.2 \%$ of patients (range, $0 \%-54.5 \%$ ) and respiratory failure occurred in $16.7 \%$ (range, $3.7 \%-45.5 \%$ ) of patients. We believe that these encouraging results should be viewed with caution because of the limitations inherent in reviewing studies carried out by surgeons highly experienced in aortic surgery, and because the analysis included a high percentage of Asian patients who may have better outcomes due to intrinsic characteristics. Nevertheless, we believe that these results at least suggest that experienced surgeons can safely perform FET surgery in patients with acute dissection patients; in-hospital mortality and stroke rates were extremely satisfactory and the risk of spinal cord injury seemed to be higher than that reported in more conservatively managed series.

Long-term data were sparse and few surpassed 1 year. One-year survival ranged from $79 \%$ to $100 \%$, and 5-year survival from $68 \%$ to $96 \%$. The pooled average of 1-year freedom from reintervention was $92.3 \%$ (range, $71.8 \%$ $100 \%$ ). Pooled average aortic remodeling, as indicated by partial/complete thrombosis of the peri-stent DTA false lumen, was $88.9 \%$ and greater than $90 \%$ in more than half of the studies with DTA imaging follow-up data available. These data suggested that aortic remodeling can be expected after FET. The $88.9 \%$ average rate of partial/complete thrombosis of the peri-stent DTA false lumen in patients undergoing the FET procedure compares favorably with that reported for conservative management, which ranges from $33.3 \%$ to $77.8 \%$ in the literature. ${ }^{22,23}$

Nevertheless, no data are available showing that patients managed by FET are associated with better long-term survival and freedom from distal aortic reintervention. This means that additional studies with longer follow-ups designed to adequately compare the FET technique with conservative arch management are strongly indicated.

\section{THE FET TECHNIQUE: IS IT JUSTIFIED IN ALL PATIENTS WITH ACUTE DISSECTION?}

Since 1996, 140 patients have undergone the FET procedure at our institution to treat patients with extensive diseased of the thoracic aorta, of whom only 10 had a type A acute aortic dissection. We have been cautious in adopting the FET procedure for acute aortic dissection for several reasons. First, not all surgeons are fully involved in our institutional FET program and we strongly discourage surgeons who have less experience with total arch replacement from using a FET. Second, not all patients are good candidates for the FET technique. These extensive operations inevitably increase the patient's surgical trauma as a result of the necessary prolonged periods of extracorporeal circulation, circulatory arrest, myocardial ischemia, and ASCP. For this reason, we use a conservative approach in elderly patients ( $>75$ years) and in those who present with a critical status, as determined by prolonged shock/tamponade, brain injury, or advanced mesenteric ischemia. Younger patients with no severe complication related to acute dissection and those with a complex distal tear or aortic rupture are the best candidates for the FET technique.

\section{CONCLUSIONS}

Surgical techniques involving stenting of the descending thoracic aorta during primary surgery for DeBakey type I acute aortic dissections are associated with promising results. When used by experienced surgeons on selected patients, these techniques do not seem to be associated with an increased risk of hospital death or stroke. In contrast, by inducing distal false lumen obliteration and thrombosis, the FET technique is likely to improve long-term survival and reduce the need for secondary or tertiary procedures. Nevertheless, additional studies designed to confirm this hypothesis are warranted. Meanwhile, in the case of acute dissection, experienced operators should perform the FET technique in appropriately selected patients.

\section{References}

1. Geirsson A, Bavaria JE, Swarr D, Keane MG, Woo YJ, Szeto WY, et al. Fate of the residual distal and proximal aorta after acute type a dissection repair using a contemporary surgical reconstruction algorithm. Ann Thorac Surg. 2007;84: 1955-64; discussion 1955-64.

2. Knipp BS, Deeb GM, Prager RL, Williams CY, Upchurch GR, Patel HJ. A contemporary analysis of outcomes for operative repair of type A aortic dissection in the United States. Surgery. 2007;142:524-8; discussion 528.e1.

3. Trimarchi S, Nienaber CA, Rampoldi V, Myrmel T, Suzuki T, Mehta RH, et al; Investigators IROAAD. Contemporary results of surgery in acute type A aortic dissection: the International Registry of Acute Aortic Dissection experience. J Thorac Cardiovasc Surg. 2005;129:112-22.

4. Westaby S, Saito S, Katsumata T. Acute type A dissection: conservative methods provide consistently low mortality. Ann Thorac Surg. 2002;73:707-13.

5. Fattouch K, Sampognaro R, Navarra E, Caruso M, Pisano C, Coppola G, et al. Long-term results after repair of type A acute aortic dissection according to false lumen patency. Ann Thorac Surg. 2009;88:1244-50.

6. Halstead JC, Meier M, Etz C, Spielvogel D, Bodian C, Wurm M, et al. The fate of the distal aorta after repair of acute type A aortic dissection. J Thorac Cardiovasc Surg. 2007; 133:127-35.

7. Hoffman A, Damberg AL, Schälte G, Mahnken AH, Raweh A, Autschbach R. Thoracic stent graft sizing for frozen elephant trunk repair in acute type A dissection. J Thorac Cardiovasc Surg. 2013;145:964-9.e1.

8. Uchida N, Katayama A, Tamura K, Sutoh M, Kuraoka M, Ishihara H. Frozen elephant trunk technique and partial remodeling for acute type A aortic dissection. Eur J Cardiothorac Surg. 2011;40:1066-71.

9. Roselli EE, Rafael A, Soltesz EG, Canale L, Lytle BW. Simplified frozen elephant trunk repair for acute DeBakey type I dissection. J Thorac Cardiovasc Surg. 2013;145:S197-201. 
10. Shrestha M, Pichlmaier M, Martens A, Hagl C, Khaladj N, Haverich A. Total aortic arch replacement with a novel four-branched frozen elephant trunk graft: first-in-man results. Eur J Cardiothorac Surg. 2013;43:406-10.

11. Sun L, Qi R, Zhu J, Liu Y, Zheng J. Total arch replacement combined with stented elephant trunk implantation: a new "standard" therapy for type a dissection involving repair of the aortic arch? Circulation. 2011;123:971-8.

12. Di Bartolomeo R, Pacini D, Savini C, Pilato E, Martin-Suarez S, Di Marco L, et al. Complex thoracic aortic disease: single-stage procedure with the frozen elephant trunk technique. J Thorac Cardiovasc Surg. 2010;140:S81-5; discussion S86-91.

13. Di Eusanio M, Schepens M, Morshuis W, Dossche K, Pacini D, Di Marco L, et al. Operations on the thoracic aorta and antegrade selective cerebral perfusion: our experience with 462 patients. Ital Heart J. 2004;5:217-22.

14. Di Eusanio M, Petridis FD, Pacini D, Di Bartolomeo R. Facilitated aortic arch repair with the frozen elephant trunk technique. Eur J Cardiothorac Surg. 2011;40:1261-2.

15. Di Eusanio M, Castrovinci S, Tian DH, Folesani G, Cefarelli M, Pantaleo A, et al. Antegrade stenting of the descending thoracic aorta during DeBakey type 1 acute aortic dissection repair. Eur J Cardiothorac Surg. 2013;45:967-75.

16. Kimura N, Tanaka M, Kawahito K, Yamaguchi A, Ino T, Adachi H. Influence of patent false lumen on long-term outcome after surgery for acute type A aortic dissection. J Thorac Cardiovasc Surg. 2008;136:1160-6, 1166.e1-3.
17. Kirsch M, Soustelle C, Houël R, Hillion ML, Loisance D. Risk factor analysis for proximal and distal reoperations after surgery for acute type A aortic dissection. J Thorac Cardiovasc Surg. 2002;123:318-25.

18. Tan ME, Morshuis WJ, Dossche KM, Kelder JC, Waanders FG, Schepens MA Long-term results after 27 years of surgical treatment of acute type a aortic dissection. Ann Thorac Surg. 2005;80:523-9.

19. Song JM, Kim SD, Kim JH, Kim MJ, Kang DH, Seo JB, et al. Long-term predictors of descending aorta aneurysmal change in patients with aortic dissection. J Am Coll Cardiol. 2007;50:799-804.

20. Sakaguchi G, Komiya T, Tamura N, Kimura C, Kobayashi T, Nakamura H, et al Patency of distal false lumen in acute dissection: extent of resection and prognosis. Interact Cardiovasc Thorac Surg. 2007;6:204-7.

21. Evangelista A, Salas A, Ribera A, Ferreira-González I, Cuellar H, Pineda V, et al Long-term outcome of aortic dissection with patent false lumen: predictive role of entry tear size and location. Circulation. 2012;125:3133-41.

22. Zierer A, Voeller RK, Hill KE, Kouchoukos NT, Damiano RJ, Moon MR. Aortic enlargement and late reoperation after repair of acute type A aortic dissection. Ann Thorac Surg. 2007;84:479-86; discussion 486-7.

23. Watanuki H, Ogino H, Minatoya K, Matsuda H, Sasaki H, Ando M, et al Is emergency total arch replacement with a modified elephant trunk technique justified for acute type A aortic dissection? Ann Thorac Surg. 2007;84 1585-91. 